\title{
REDES CRIMINALES \\ Y CORRUPCIÓN EN LA ERA \\ DEL MICROTRÁFICO \\ Y EL NARCOMENUDEO
}

Leonardo Raffo López*
Diego Gómez Calderón**

Tn artículo reciente de la revista Semana se titula "Viaje al infierno" , en alusión al caso del Bronx, una de las más complejas ollas criminales de Bogotá. ¿Qué tipo de actividades criminales se realizaban allí para que fuese asociado al "infierno"? Según el artículo, en las casi ocho cuadras del Bronx había microtráfico, expendio de drogas, prostitución infantil, desapariciones forzadas, descuartizamientos humanos, secuestro y apuestas ilegales. Un escenario de terror, situado a 800 metros de la Presidencia de la República, el Congreso, la Alcaldía Mayor, la Guardia Presidencial y el Comando de la Policía Metropolitana; es decir, en el epicentro de los altos poderes.

Surgen varios interrogantes: ¿qué dinámicas sociales subyacen a la connivencia entre agentes legales e ilegales?, ¿qué tipo de contiendas se libran entre autoridades y bandas criminales para dominar un territorio y realizar allí actividades ilegales?, ¿qué efectos sociales ha generado la prohibición de la cadena productiva de drogas ilícitas? Todos ellos motivan el presente trabajo.

E1 Bronx es una expresión extrema de una realidad: la lucha contra el narcotráfico ha provocado procesos sociales perjudiciales, y no solo no ha eliminado el problema, sino que ha hecho más complejos sus

* Magíster en Economía, profesor titular y miembro de los grupos de investigación de Desarrollo Económico, Crecimiento y Mercado Laboral e Investigación de Conflicto, Aprendizaje y Teoría de Juegos de la Universidad del Valle, Cali, Colombia, [leonardo.raffo@correounivalle.edu.co].

** Magister en Economía Aplicada y profesor de la Universidad Autónoma de Occidente, Cali, Colombia, [diego@correounivalle.edu.co]. Fecha de recepción: 19-08-2016, fecha de modificación: 04-08-2017, fecha de aceptación: 04-09-2017. Sugerencia de citación: Raffo L., L. y Gómez C., D. (2017). Redes criminales y corrupción en la era del microtráfico y el narcomenudeo", Revista de Economía Institucional 19(37), 227-261. Dor: https://doi.org/10.18601/01245996.v19n37.12

1 Semana 1779, 5-12 de junio de 2016. 
efectos, sobre todo en los países productores de drogas ilegales. E1 Bronx no es una realidad aislada, es resultado de complejas contiendas por perpetuar una actividad que por sus altas ganancias encuentra formas y métodos para reproducirse y fortalecerse.

Este trabajo analiza el microtráfico de drogas ilícitas para identificar y analizar los principales agentes, relaciones y procesos que determinan este tipo de actividades. Con este fin se construye un modelo teórico que permite examinar las interacciones estratégicas entre los tipos de agentes. El análisis parte del concepto de dominio territorial, el cual es esencial en la cadena de microtráfico y narcomenudeo en los mercados de drogas ilícitas actuales. La hipótesis es que el microtráfico es una estrategia adaptativa de diversificación del riesgo, cuyo resultado práctico es el aumento de la eficiencia en la cadena productiva.

La pregunta principal es: ¿cuáles son los agentes, relaciones y procesos que caracterizan el microtráfico y el narcomenudeo? De esta se deprenden preguntas más específicas: ¿cuáles han sido las tendencias del narcotráfico y la violencia en Colombia durante los últimos años?, ¿cuál es el papel del dominio territorial y de la corrupción?, ¿cuáles son los actores clave en el microtráfico y el narcomenudeo?, ¿qué rol cumplen las redes criminales?

Los objetivos específicos son: 1. Identificar las principales tendencias del narcotráfico y la violencia en Colombia durante los últimos años; 2. Analizar el rol que juegan el dominio territorial y la implementación de diversas estrategias de corrupción por parte de los agentes ilegales y las bandas criminales en el microtráfico y el narcomenudeo; 3. Identificar los agentes clave en las organizaciones ilegales de microtráfico-narcomenudeo, y 4. Determinar las características generales y el rol de las redes de vínculos sociales criminales en las organizaciones ilegales.

La importancia del primer objetivo radica en que permite hacerse una idea de la evolución del narcotráfico durante las últimas décadas. Esto se logra en la primera sección del trabajo. El segundo objetivo es esencial para entender el rol de los procesos de corrupción que desarrollan los agentes ilegales en su relación con determinados territorios bajo su acción o control; este se alcanza en la primera sección y también en las siguientes al plantear y resolver el modelo analítico propuesto. E1 tercer objetivo, identificar los agentes clave en el contexto actual, también se alcanza en la primera sección. El cuarto objetivo permite examinar los vínculos sociales de los criminales y su importancia en el funcionamiento de las organizaciones ilegales; 
el modelo que se propone es útil para entender la forma en que las redes criminales, en particular las de distribución y tráfico de drogas, moldean las actividades ilegales.

En la primera sección se hace un análisis conceptual del microtráfico y el narcomenudeo que permite entender los rasgos básicos de los actuales mercados de drogas ilícitas. En la segunda y en la tercera se presenta y se resuelve un modelo formal. En la última se hace un comentario final a manera de conclusión.

\section{EL MERCADO ACTUAL: MICROTRÁFICO Y NARCOMENUDEO}

E1 narcotráfico, más que una hidra invencible (Ortiz, 2002), es una compleja red de interrelaciones estratégicas que evoluciona en forma racional ante los desafíos que impone la lucha de los Estados. Entender la estructura del narcotráfico va más allá de analizar encadenamientos productivos; pues implica examinar contiendas entre el Estado y los agentes ilegales ${ }^{2}$ por establecer y controlar instituciones que regulan el orden de numerosas comunidades y grupos sociales. La base de esa contienda es la cooptación del territorio por los agentes ilegales.

Como plantea Duncan, es importante preguntar: “jpor qué [...] unas organizaciones criminales han sido capaces de gobernar una porción significativa de la sociedad desde el control del narcotráfico?” $(2014,13)$. Su respuesta es muy intuitiva dada nuestra realidad social: el capital de las drogas ha generado mayor inclusión y participación en los mercados para las poblaciones socialmente marginadas, que han encontrado en la criminalidad un canal de movilidad social. "El crimen se convirtió en una oportunidad para que unos individuos provenientes de sectores excluidos accedieran a una posición social" (ibíd., 14), es decir, el capital de la droga funciona como medio de inclusión social.

Sin embargo, el narcotráfico, además de generar un capital que podríamos denominar como benevolente (inclusión derivada de la actividad criminal) -lo cual es un producto residual-, tiene como eje central la acumulación de capital proveniente de ganancias extraordinarias, aun en el largo plazo. Las ganancias extraordinarias han permitido reconfigurar la contienda Estado-bandas criminales (Bacrim), no en función exclusiva de disputas armadas, sino de la capacidad de corromper a partir de dicho capital. Así, la contienda se manifiesta en la capacidad de capturar el aparato institucional legal que controla, vigila y castiga las actividades criminales, el cual es incorporado a la

\footnotetext{
${ }^{2}$ Individuos, grupos u organizaciones que subvierten el orden establecido mediante la violencia o instituciones informales fuera de la ley.
} 
ilegalidad por la rentabilidad que genera. "La decisión de reprimir o aceptar un soborno es más compleja cuando la actividad criminal-en este caso el narcotráfico- está articulada a amplias demandas sociales" (ibíd., 15); es decir, el capital del narcotráfico no solo genera inclusión social, también reconfigura la contienda Estado/bacrim; lo cual hace más complejo el diagnóstico de la actividad ilegal.

Ahora bien, el espacio natural de contienda en el desarrollo de un mercado ilegal se sintetiza en el territorio, y el narcotráfico no es la excepción. Sin embargo, en lugar de la imposición de un monopolio del Estado de corte weberiano, en este caso se trata del ejercicio de un oligopolio de coerción, por parte del Estado y las organizaciones criminales, en el intento de ejercer control social (ibíd.). La contienda Estado/bacrim por el territorio se libra dentro de fronteras invisibles, definidas por el poder corruptor del capital del narcotráfico sobre los agentes del Estado y, en últimas, por el combate directo entre las partes (violencia) que determina los espacios de control y usufructo del territorio. La territorialización de la actividad criminal alcanza mayor importancia con la estrategia de consolidar el mercado interno, estrechamente relacionada con la irrupción del microtráfico.

La consolidación del mercado interno, como parte de una reacción estratégica de las bandas criminales, por la intensidad de la lucha internacional contra esta actividad, permite intuir la gran capacidad de reproducción y adaptación del narcotráfico a los desafíos que impone su persecución con el propósito de crear las condiciones para la comisión de diversos tipos de delitos correlacionados (de León et al., 2016). Por tal razón la represión al narcotráfico, basada en una política unidireccional contra la oferta, conduce paradójicamente, en la práctica, a un aumento de la rentabilidad y al fortalecimiento de las bandas criminales basadas en el narcotráfico.

Múltiples trabajos desde la economía de los bienes ilegales y la economía del crimen sustentan lo anterior; sin embargo la hipótesis alternativa que se sostiene en este trabajo es que la focalización en la oferta, como principal instrumento de persecución al narcotráfico, no solo permite una respuesta estratégica de estos agentes que componen la red de drogas ilícitas sobre dicho mercado, sino que genera la consolidación de submercados derivados del mercado principal (sustancias psicoactivas), lo cual lleva a un mayor poder territorial; es decir, el territorio se convierte en el espacio de influencia y control del crimen (ibíd., 2016). 


\section{LA CADENA PRODUCTIVA EN EL CONTEXTO ACTUAL}

En la literatura en la materia se han propuesto formas distintas, aunque cercanas, de descomponer la cadena de producción del narcotráfico. De León y Salcedo (2014) centran su estudio en el análisis de las innovaciones relacionadas con el sistema de transporte, de ahí que traten el transporte como un eslabón esencial; además, descomponen el proceso en cuatro etapas: producción, transporte, distribución y lavado. Otros trabajos, como el de Duncan (2005), dividen el proceso en cuatro etapas diferentes: siembra (de coca y amapola), transformación en drogas aptas para el consumo, contrabando a los mercados internacionales, y legalización de las ganancias. Raffo y Segura (2015), por otra parte, dividen el proceso en cinco etapas: siembra de las plantas ilícitas, producción y transporte de drogas a nivel doméstico, transporte transnacional desde países productores a países consumidores, distribución y comercialización en el extranjero o en el mercado interno, lavado de activos y reinversión de ganancias.

Otros autores proponen una división más fina de la cadena productiva. En el caso de la cocaína, Tickner et al. (2011) la desagregan en doce eslabones, mientras que Mejía y Rico (2011) identifican solo siete. Todos estos trabajos convergen en identificar los eslabones fundamentales relacionados con la producción y el transporte, la distribución y el lavado, pero en ocasiones los describen utilizando términos diferentes y dando mayor énfasis a distintas fases según los objetivos y enfoques particulares de sus trabajos.

De esta forma, es didáctico concebir el narcotráfico como un sistema que se compone de cuatro subsistemas básicos: producción, distribución, comercialización y capital circulante (de León et al., 2016). Sin embargo, para los fines de este trabajo, en el contexto actual del microtráfico de drogas y enfocándonos en la comercialización de los estupefacientes en los mercados internos, proponemos describir la cadena productiva descomponiéndola solo en cuatro eslabones: producción, microtráfico, narcomenudeo y reinversión de ganancias. Cada eslabón desarrolla fenómenos concretos con lógicas diferenciales en la cadena productiva, pero, a su vez, en la contienda Estado/bacrim.

La producción ha sido descrita de forma amplia en otros trabajos ${ }^{3}$, así que no se aborda aquí. El microtráfico consiste en el "transporte de droga mediante [varias] modalidades: adherida, ingerida, elaborada, introducida, contenida, impregnada y diluida" (De León et al., 2016, 10). En el microtráfico se manifiesta la respuesta racional de

\footnotetext{
${ }^{3}$ Ver de León y Salcedo (2014), Tickner et al. (2011), Mejía y Rico (2011) y Raffo y Segura (2015).
} 
adaptación y diversificación del riesgo de las bandas criminales frente a la persecución internacional del narcotráfico.

Desde los años setenta Colombia es uno de los principales países productores de drogas ilícitas, y hoy es el primer productor de cocaína (UNODC, 2015 y 2016). En este escenario, el principal objetivo de la producción y distribución de drogas ilícitas por parte de las bandas criminales nacionales, hasta mediados de la década pasada, era abastecer los mercados internacionales.

Pero la intensidad de las políticas nacionales e internacionales de control de la oferta generó un escenario muy inestable, en términos del riesgo para los agentes de la red nacional de narcotráfico. Por ello el mercado interno se convirtió en una alternativa de diversificación operacional (y de riesgo) de las bandas criminales, que se evidencia en dos aspectos señalados por de León et al. (2016):

1. Segmentación de la cadena en eslabones cada vez más pequeños y numerosos (reconfiguración de la organización narcotraficante: de grandes carteles a pequeñas bandas).

2. Proliferación de múltiples organizaciones criminales de menor escala focalizadas en la ampliación del mercado interno.

Desde esta perspectiva se puede plantear que el microtráfico, más allá de ser un eslabón de la cadena productiva, hoy corresponde a una estrategia adaptativa de diversificación del riesgo, la cual ha permitido desarrollar un conjunto de estrategias de especialización y fortalecimiento que aumentan la eficacia y la eficiencia del negocio.

El narcomenudeo consiste en la venta de dosis personales y de aprovisionamiento. Este ejerce un alto impacto en las urbes modernas, ya que la comercialización al por menor requiere el control total de ciertas zonas urbanas, lo cual consolida la aparición de lo que de León et al. (2016) llaman zonas de impunidad. Las ollas son una especie de guetos criminales que llevan al límite la cooptación del territorio por parte de las bandas criminales. Pero su principal estrategia, en el espacio del narcomenudeo -comúnmente confundido con el microtráfico-, es consolidar zonas de expendio estratégicas que permitan aumentar y diversificar el mercado. Con ese fin las bandas criminales implementan diversos mecanismos de violencia y corrupción para cooptar territorios y lograr menor visibilidad social.

El último eslabón permite reinvertir las ganancias y colocar el dinero obtenido en el sistema económico legal. Esta fase se materializa en el lavado de activos (Raffo y Segura, 2015; de León et al., 2016). En lo que sigue conviene examinar con mayor profundidad las interrelaciones entre el microtráfico y el narcomenudeo. 
Como confirma Duncan, "el narcotráfico es en esencia una empresa de reducción de riesgos" $(2014,39)$; pero el punto clave es que esta realidad llevó, incluso desde la consolidación del mercado de la cocaína durante los años ochenta, a que el narcotráfico se consolidara como un sistema de producción de poder. Desde esta perspectiva, cada uno de los eslabones de la cadena define formas diferenciales de optimizar el nivel de riesgo ligadas a mecanismos específicos de cooptación del poder territorial. Con la reestructuración operativa del narcotráfico en Colombia desde la década pasada, que llevó a reorientar una parte importante de las ventas hacia los mercados internos, las actividades de distribución de las drogas cobraron un papel inédito.

En el escenario de consolidación del mercado interno, el microtráfico y el narcomenudeo de drogas ilícitas constituyen los subprocesos fundamentales de este encadenamiento productivo. Según esto, el microtráfico se convierte en el principal desafío de las autoridades nacionales, ya que es precisamente la consolidación de rutas internas de distribución de drogas ilícitas lo que potencia en la actualidad diversas actividades ilegales en Colombia.

En este sentido, las autoridades de control deben aumentar los esfuerzos en procesos de inteligencia del mercado de drogas ilícitas, dado que la identificación de conductas punibles se da solo bajo condiciones de flagrancia o producto de una profunda investigación criminal. Esto exige un umbral alto de eficiencia para las autoridades de control, que en ocasiones no es suficiente cuando entran en acción distintos mecanismos de corrupción por parte de las bandas criminales. Se trata de mecanismos sofisticados con los que se procura neutralizar la acción de las autoridades de control.

De este modo, la consolidación del microtráfico y el narcomenudeo, como estrategias de diversificación del riesgo de la actividad criminal del narcotráfico, se basa en el diseño de un mecanismo óptimo de corrupción, que permita consolidar y profundizar el mercado interno, generar barreras de entrada para el sostenimiento de ganancias positivas aun en el largo plazo y, a su vez, cooptar el territorio como expresión máxima de poder criminal.

En síntesis, en condiciones de prohibición, persecución y penalización del narcotráfico las ganancias no están aseguradas. Como dice Ortiz, "la actividad del narcotráfico es más costosa por la prohibición misma: esta le otorga valor a las indulgencias de los agentes oficiales" $(2002,5)$; además, con la confiscación de un cargamento se procede a destruir el producto, lo cual impone un costo adicional (entre otros 
costos), principalmente por la pérdida de mercados ${ }^{4}$. Todo esto, en suma, deriva en la búsqueda incesante de las bandas criminales por cubrirse en riesgo, fortaleciendo diferentes estrategias, entre ellas el microtráfico, la cual no solo ha permitido consolidar el mercado interno de drogas ilícitas en Colombia, sino la expansión de otros mercados ilegales correlacionados: hurto, extorsión, secuestro extorsivo, entre otros. Estos mercados alternativos permiten cooptar el territorio y expandir el mercado principal de drogas ilegales.

Ahora bien, aparte del funcionamiento de los eslabones propiamente productivos, debido a su naturaleza ilegal se requieren otras estructuras subsidiarias para su funcionamiento: estructuras de defensa y corrupción.

\section{ESTRUCTURAS SUBSIDIARIAS DE DEFENSA Y CORRUPCIÓN}

Además de la tecnología de producción propia de cualquier actividad económica, para su funcionamiento y reproducción el narcotráfico requiere una tecnología para el conflicto y la corrupción que garantice la operación de dispositivos de violencia, coerción y corrupción (Raffo y Segura, 2015). Según estos autores, esta "tecnología”, que podría considerarse un tipo particular de tecnología del conflicto (Hirshleifer, 1988, 1991a y 1991b), depende del funcionamiento de vínculos y redes sociales "que soporta todas las actividades de seguridad y corrupción que buscan la supervivencia de la organización, y garantizan la operatividad de la cadena productiva al margen de la ley" (Raffo y Segura, 2015, 184).

De León y Salcedo (2014) señalan que la seguridad y la violencia al servicio de los narcotraficantes pueden ser proporcionadas por grupos de seguridad propios, bandas criminales o grupos violentos externos. También resaltan la importancia de la corrupción que ejercen sobre las autoridades de control mediante sobornos a funcionarios o a miembros del sector privado.

\section{UN MODELO DE MICROTRÁFICO DE DROGAS}

Una contribución de este modelo es la incorporación al análisis de la incidencia de las redes de tráfico y distribución de drogas ilícitas (RTD), las cuales pueden concebirse como una clase particular de redes criminales al servicio de las organizaciones ilegales que se encargan del tráfico y distribución de los estupefacientes. La otra contribución es el análisis de las decisiones relacionadas con la corrupción

\footnotetext{
${ }^{4}$ Ver Ortiz (2002).
} 
por parte de los agentes ilegales en el contexto del microtráfico y el narcomenudeo.

E1 desarrollo de la contienda autoridades de control/bacrim define un cambio en la orientación espacial del producto mismo (sustancias ilícitas), lo cual ha originado el microtráfico como respuesta racional de las bandas criminales en la consolidación de un mercado interno, impulsado por los altos costos de proveer los mercados internacionales; pero a su vez, ha estimulado múltiples mecanismos de apropiación del territorio, que pueden ser esquematizados mediante un juego en dos etapas.

En la primera etapa se define la probabilidad de detectar una transacción ilegal (contienda), considerando exógenos los esfuerzos del gobierno en el desarrollo de la contienda. En la segunda etapa se desarrolla un modelo à la Cournot, con una estructura de mercado oligopólica y redes regulares, definiendo una función de costos esperados de la actividad ilegal en función de una sanción unitaria esperada, que corresponde al producto de la probabilidad de detección y arresto, y de ser multado, si el agente es capturado y sentenciado.

E1 modelo analítico se concentra en las interacciones estratégicas de carácter dinámico (secuencial) entre el microtráfico de drogas en cabeza de los traficantes y agentes de defensa y corrupción al servicio de los primeros en una primera etapa del juego. Estos últimos ejecutan las labores correspondientes a las estructuras de violencia, coerción y corrupción de las organizaciones ilegales (Raffo y Segura, 2015). Entre tanto, en la segunda etapa del juego los distribuidores al por menor toman las decisiones de venta de los estupefacientes conociendo las elecciones de corrupción y producción de los demás agentes en la primera etapa del juego, pero también interactuando estratégicamente entre sí en un modelo con competencia à la Cournot.

\section{LA PRIMERA ETAPA}

A lo largo del juego se supone que en el mercado de drogas ilícitas interactúan tres tipos de agentes: $n \geq 1$ traficantes o distribuidores de drogas, autoridades de control y compradores de drogas.

Sin embargo, se supone que, mientras en la primera etapa las elecciones de corrupción dependen de las decisiones de las bacrim en cabeza de los traficantes de drogas, las decisiones de venta de drogas en la segunda etapa dependen de los distribuidores de drogas. Como se supone que hay integración vertical de las actividades ilícitas, tanto 
los traficantes como los distribuidores al por menor se supone que enfrentan las mismas funciones de ganancias esperadas ${ }^{5}$.

También se supone que todos los traficantes o distribuidores al por menor se articulan a una red de tráfico y distribución de drogas (RTD), $g$, constituida por un conjunto de nodos $(N)$ y un conjunto de vínculos entre ellos $(V)$; el conjunto de nodos corresponde al conjunto de $n$ traficantes o vendedores de drogas en el mercado. Si el traficante $i$ tiene una relación social con $j, g_{i j}=1$; en caso contrario $g_{i j}=0$. Siguiendo a Calvó y Zenou (2004) y a Raffo (2015), y por parsimonia, se supone que $g$ representa un grafo no dirigido, de modo que $g_{i j}=j_{i j}, \forall_{i}, \forall_{j} \in N$. Este supuesto implica que los vínculos sociales de los traficantes en su RTD son recíprocos, lo que es lógico en redes criminales o ilegales porque los vínculos se basan en la confianza y la lealtad mutuas (Raffo, 2015).

Se define la probabilidad de detectar una transacción ilegal $(\varphi)$, como resultado de una contienda entre las autoridades de control y las bandas criminales. La disputa por el territorio es la esencia de dicha contienda, dado que las partes buscan controlar las actividades a desarrollar en los territorios, para lo cual deben invertir recursos (en términos monetarios principalmente), que generan fuerzas de choque y definen la probabilidad de detección $(\varphi)$; y en últimas, la efectiva cooptación, o no, del territorio.

La cooptación no debe entenderse como una apropiación total de un territorio específico, sino como una suerte de oligopolio de coerción, donde se definen cuotas de apropiación, que permiten el actuar delictivo en dichos espacios. Las cuotas diferenciales en diversos espacios del territorio, que establecen mayor o menor nivel de criminalidad, están en función del nivel de recursos disponibles para el desarrollo de la contienda. Es en este espacio donde, además de sus múltiples facetas, aparece el narcotráfico como productor de poder para el control territorial y la protección de los agentes criminales.

Toda protección en el negocio deriva en una amenaza, por lo tanto, solo es posible ofrecer protección si se cuenta con la posibilidad de amenazar; es decir, la capacidad de neutralizar las distintas amenazas que se engendran en el negocio. Esta razón sustantiva de la búsqueda de protección como elemento central del negocio conlleva una paradoja social: las dos principales formas de protección están en la coerción privada y en la influencia sobre el Estado. Esto conduce irremediablemente a que la contienda autoridades de control/bacrim se sustente en una lucha directa vía ejércitos privados contra ejércitos de control

\footnotetext{
${ }^{5}$ Un modelo más realista debería separar los problemas de elección de ambos tipos de agentes, y desagregar verticalmente la cadena productiva, al menos en dos etapas claramente diferenciadas.
} 
estatal, o en actividades de chantaje y corrupción a políticos o agentes grises (Garay y Salcedo, 2012) que tienen capacidad para influir en los mecanismos de detección y arresto de los criminales.

Lo interesante de esta contienda es, según diferentes autores ${ }^{6}$, que las bandas criminales cada vez más le apuestan a la segunda estrategia de protección, es decir, articular a las autoridades de control con sus intereses, lo cual pervierte el sistema social de control y seguridad, ya que convierte en parte de las estructuras criminales a las autoridades de control.

Según lo anterior, la probabilidad de detectar una transacción ilegal está dada por:

$\varphi=G\left(1-\tilde{c}_{1}\right) ;$

donde $0<\mathrm{G}<1$, y $0<\tilde{c}_{1}<1$; $G$ representa el esfuerzo, en términos monetarios, de las autoridades de control, para controlar la mayor proporción de territorio; $\mathrm{y} \tilde{c}_{1}$ es el esfuerzo, en términos monetarios, de las bacrim por controlar el territorio. Esta variable debe entenderse como un índice integral de cooptación del territorio, el cual involucra corrupción, violencia directa y ampliación de submercados ilegales.

Esta probabilidad de detección expresa la contienda que se desenvuelve entre las autoridades de control, por un lado, y las bandas criminales, por el otro. A diferencia de la modelación tradicional de contiendas $^{7}$, debido a que se trata de una probabilidad de captura, en este trabajo la probabilidad de éxito se modela como una función de captura inspirada en los trabajos de Calvó y Zenou (2004), Ballester et al. (2010) y Raffo y Segura (2015), y no como la función de éxito en una contienda tradicional. Las dos variables que determinan la función se normalizan a 1 para acotar la probabilidad de captura entre 0 y 1 . Además, se consideran dadas las elecciones estratégicas de las autoridades de control, pues no se modela su comportamiento. Por ello $G$ se considera exógena ${ }^{8}$.

En el modelo se supone que hay integración vertical de las actividades de microtráfico-narcomenudeo. Sin embargo, la idea es que, mientras que en la primera etapa las elecciones corresponden a las

${ }^{6}$ P. ej., Duncan (2014), de León (2016), Grossman y Mejía (2005), Mejía y Restrepo (2008) y Garay y Salcedo (2012).

7 Ver Hirschleifer (1988, 1991a y 1991b), Skaperdas (1991, 1992a y 1992b), Skaperdas y Syropoulos (1995 y 2001).

${ }^{8}$ En futuros trabajos se podría incorporar el análisis de las elecciones estratégicas de inversión en recursos que hacen las autoridades de control para capturar y detectar cada transacción ilegal. Esto podría hacerse en el contexto de un juego simultáneo con información imperfecta y completa, o como otra etapa del juego secuencial. No obstante, por parsimonia en este trabajo $G$ se trata como una variable exógena. 
decisiones de corrupción de los micro-traficantes, las elecciones de distribución y venta de estupefacientes en la segunda etapa están ligadas a las elecciones de los distribuidores al por menor de las drogas en el contexto de las actividades típicas de narcomenudeo. Una versión más avanzada del modelo podría desagregar en dos eslabones productivos la cadena de producción de microtráfico-narcomenudeo, cada uno con funciones de ganancias esperadas distintas. Sin embargo, esto no se hace en este artículo al suponer integración vertical de la cadena, aunque sí se distinguen las elecciones de los dos tipos de agentes con base en el orden del juego secuencial.

Por otra parte, si bien en el modelo no se incorporan aspectos espaciales de manera explícita, se supone que cada agente ilegal domina un territorio en el que despliega sus actividades ilegales, en las fases de microtráfico y narcomenudeo.

\section{LA SEGUNDA ETAPA}

En la segunda etapa se desarrolla un modelo tipo Cournot, con una estructura de mercado oligopólica y redes regulares. Esta parte corresponde al modelo elaborado por Raffo (2015), el cual se basa en la estructura propuesta por Poret y Téjedo (2006).

Las posibilidades transaccionales del mercado dependen del resultado de la contienda territorial. En consecuencia, se define una medida de intensidad de la represión, $\varepsilon$, en función de una sanción unitaria o multa esperada que enfrentan los agentes ilegales -los microtraficantes en caso de ser capturados-, s, y de la probabilidad de detectar una transacción ilegal, $\varphi$ :

$\varepsilon=s \varphi$

Esta medida de intensidad de la represión en estricto corresponde a una sanción unitaria esperada por transacción para un monopolio (Poret y Téjedo, 2006) o para un agente asilado (Raffo, 2015).

Poret y Téjedo (2006) definen una probabilidad de detección y arresto $\left(d_{i}\right)$, con base en la siguiente estructura:

$d_{i}=\frac{d q_{i}}{q}$

La probabilidad de detectar y arrestar (PDA) a un agente criminal por una transacción ilegal depende de la proporción de las ventas de $i$ en el total de ventas del mercado; en la notación de Poret y Téjedo (2006), $q_{i}$ son las ventas ilegales del traficante $i, q$ las ventas del mercado y $d$ 
un parámetro positivo menor que 1 , el cual corresponde en su modelo a la probabilidad de detectar una transacción ilegal.

Por otra parte, Raffo (2015), a partir del análisis de Poret y Téjedo (2006), define la PDA incorporando un análisis de redes. Establece que la PDA depende de la centralidad de grado de un traficante $\left(c_{i}(g)\right)$ en la RTD en que se desenvuelve. Dicha centralidad de grado mide el número de contactos directos que tiene un traficante (con otros agentes de la misma red) en relación con el número total de agentes en la red, y se define así:

$$
\mathrm{c}_{\mathrm{i}}(\mathrm{g})=\frac{\delta_{\mathrm{i}}(\mathrm{g})}{\mathrm{n}-1}
$$

donde $d_{i}(g)$ corresponde al grado del agente $i$ en la red $g$, o sea al número de vínculos directos que tiene en esa red. Así, incorporando redes, la PDA de un traficante se puede representar así:

$$
f_{i}(\varphi, \mathrm{g})=\left\{\begin{array}{c}
\frac{\varphi c_{i(g)}}{c_{i}(g)+\sum_{j \neq i}^{n} g_{i j} c_{j}(g)} s i(\exists j)\left(g_{i j}=1\right) \\
\varphi s i(\forall j \neq i)\left(g_{i j}=0\right) \text { on } n=1
\end{array}\right.
$$

Ahora, sea $N_{i}(g)=\left\{i j \in g \mid g_{\mathrm{ij}}=1\right\}$ la vecindad de $i$ en $g^{9}$; teniendo en cuenta que $c_{i}(g)=\frac{\delta_{i}(g)}{n-1}$ y simplificando, la PDA se puede reescribir así:

$$
f_{i}(\varphi, \mathrm{g})=\left\{\begin{array}{l}
\frac{\varphi \delta_{i(g)}}{\delta_{i}(g)+\sum_{j \in N_{i}(g)} \delta_{j}(g)} s i(\exists j)\left(g_{i j}=1\right) \\
\varphi s i(\forall j \neq i)\left(g_{i j}=0\right) \text { on } n=1
\end{array}\right.
$$

Esta función permite incorporar al modelo el análisis de las redes sociales -en ese caso de las RTD-, al tener en cuenta el nivel de centralidad de grado de cada traficante, así como el de sus vecinos (sus contactos directos) en la red. Por ello es central en el análisis. La idea que expresa (3) es que la PDA de un distribuidor minorista de drogas es directamente proporcional al número de vínculos directos que posee con otros traficantes. Diversos trabajos pertenecientes al campo de la criminología y al estudio de las organizaciones que utilizan análisis de redes sociales han planteado que la PDA de los criminales tiende a estar correlacionada empíricamente de forma directamente proporcional con la centralidad de grado que sostienen en las redes

\footnotetext{
${ }^{9}$ La vecindad de $i$ en $g$ corresponde al espacio social constituido por sus contactos directos en $g$.
} 
criminales en donde se desempeñan (Baker y Faulkner, 1993; Morselli, 2009 y 2010; Calderoni, 2011).

Nótese que en (3) la PDA de cualquier traficante $i$ depende en forma directamente proporcional de su grado $d_{i}(g)$ en la red criminal $g$, pero en forma inversamente proporcional del grado de sus vecinos. Este segundo efecto captura el efecto positivo para dicho agente que producen los contactos de sus vecinos, o sea los vínculos directos de sus propios contactos directos. La idea de este segundo efecto es que un traficante, aunque tiende a ser más visible frente a la ley entre más contactos directos tenga ceteris paribus, tiende a ser menos visible entre más vínculos directos tengan sus contactos directos ceteris paribus. La incorporación de $d_{i}(g)$ en el denominador de (1) permite normalizar $f_{i}(\varphi, g), \mathrm{y}$, en consecuencia, acotar su PDA entre 0 y 1 .

Siguiendo a Poret y Téjedo (2006) y a Raffo (2015), la multa por arresto se define como una función lineal de las ventas de drogas de cada traficante:

$S_{i}\left(q_{i}\right)=s q_{i}$

donde $s$ es un parámetro positivo que capta el efecto de un incremento marginal en las cantidades vendidas sobre las ventas de un traficante. Esta función muestra que el castigo o pena que enfrentan los traficantes en caso de ser capturados es directamente proporcional a la cantidad de drogas que venden en los procesos de narcomenudeo. Aunque esta pena podría expresarse en términos del tiempo de arresto, juicio y/o encarcelamiento de los traficantes, aquí se expresa en términos monetarios.

Definidos los dos mecanismos con los cuales las autoridades de control ejercen represión contra la oferta de drogas ilícitas, se puede definir una estructura de costos esperados derivados de dicha represión.

$C_{i}\left(q_{i}, \varepsilon, g\right)=\left\{\begin{array}{l}\frac{\varepsilon \delta_{i(g)}}{\delta_{i}(g)+\sum_{j \in N_{i}(g) \delta_{j}(g)}} q_{i} \text { si }(\exists j)\left(g_{i j}=1\right) \\ \varepsilon q_{i} s i(\forall j \neq i)\left(g_{i j}=0\right) \text { on } n=1\end{array}\right.$

donde $\varepsilon=s \varphi$ es la función de sanción unitaria esperada.

Esta función corresponde a una función de costos derivados de la represión, la cual es enfrentada por cada traficante, y como puede observarse, depende de forma directamente proporcional del nivel de sus ventas individuales, de su PDA y de la intensidad de la represión que ejercen las autoridades, captada por $\varepsilon=s \varphi$. 
Además, se define un costo marginal de corrupción $\eta$, el cual capta el efecto marginal del nivel de corrupción en la estructura de ganancias de las bandas criminales, costo de corrupción asociado a la territorialidad de las bandas criminales. Por sencillez, se obvian otros costos que pueden enfrentar los distribuidores en la comercialización al por menor de las drogas ilegales.

Por último, siguiendo a Poret y Téjedo (2006) y a Raffo (2015) se supone una función inversa de demanda de drogas ilícitas lineal del tipo:

$P(Q)=\left\{\begin{array}{c}1-Q \text { si } Q \in(0,1) \\ 0 \text { si } Q \in[1, \infty]\end{array}\right.$

donde $Q=\sum_{i=1}^{n} q_{i}$

Esta función capta la forma de la demanda de drogas por parte de los consumidores en los mercados ilegales ${ }^{10}$. Se trata de una estructura sencilla de demanda que capta la relación inversa que existe entre las cantidades vendidas de drogas y sus precios al por menor en los mercados de ventas para su consumo final.

Incorporando redes regulares al modelo, la segunda etapa se puede resolver fácilmente hallando un equilibrio simétrico de Nash para las ventas individuales de los traficantes. Por tanto, tenemos $\delta_{i}(g)=\delta \geq 0 \forall i \in N$; donde $\delta$ corresponde al grado medio de los agentes en la red. La PDA se puede simplificar así:

$f(\varphi, \delta)=\frac{\varphi \delta}{\delta+\sum_{j \in N_{i}(g)} \delta}$

Lo que simplificando equivale a $f(\varphi, \delta)=\frac{\varphi}{1+\delta}$. Incorporando esta expresión en (5), los costos derivados de la represión quedan así:

$C_{i}\left(q_{i}, \varepsilon\right)=\left\{\begin{array}{c}\frac{\varepsilon}{1+\delta} q_{i} s i(\exists j)\left(g_{i j}=1\right) \\ \varepsilon q_{i} s i(\forall j \neq i)\left(g_{i j}=0\right) \circ n=1\end{array}\right.$

Dada la estructura secuencial del modelo, este se resuelve por inducción hacia atrás.

${ }^{10}$ Con una función de demanda lineal los consumidores de drogas ilegales poseen funciones de utilidad cuadráticas en función del consumo de drogas y de un numerario que capta el consumo del resto de bienes en la economía, el cual entra de forma lineal en la función. En el artículo no se desarrolla esta parte por las limitaciones de espacio. 


\section{DESARROLLO Y SOLUCIÓN DEL MODELO}

\section{SOLUCIÓN DE LA SEGUNDA ETAPA}

Cada vendedor $i$ de drogas ilícitas (narcomenudeo) enfrenta el siguiente problema de optimización de las ganancias esperadas con respecto a sus ventas estupefacientes, $q_{i}$ :

$\operatorname{Max} \pi_{i}\left(q_{i}, q_{-i}, \widetilde{c_{l}}, \varepsilon, \delta\right)=(1-Q) q_{i}-\frac{\varepsilon}{1+\delta} q_{i}-\eta \widetilde{c_{l}}$

donde el término $\eta \widetilde{c_{l}}$ representa los costos totales que enfrenta cada traficante como resultado de los recursos invertidos en niveles de corrupción, $\widetilde{c_{l}} ; \eta$ representa el costo marginal de invertir una unidad de recursos en corrupción.

La condición de primer orden $\left[\frac{\partial \pi_{i}(\cdot)}{\partial q_{i}}=0\right]$ viene dada por:

$1-2 q_{i}-\sum_{j \neq i} q_{j}-\frac{\varepsilon}{1+\delta}=0$

Despejando $q_{i}$ tenemos:

$q_{i}^{*}=R_{i}\left(q_{-i}, \varepsilon, \delta\right)=\frac{1-\sum_{j \neq i} q_{j}-\frac{\varepsilon}{1+\delta}}{2}$

(9) define la función de reacción de las ventas del traficante $i$ en función de las ventas del resto de traficantes del mercado $\left(q_{-i}\right)$ Dado que se definió la presencia de redes regulares, se obtienen los resultados del mercado desde la perspectiva del equilibrio simétrico de Nash $\left(q^{*}=q_{1}^{*}=\cdots=q_{n}^{*}\right)$. De (9) se obtiene:

$q^{*}(\varepsilon, n, \delta)=\frac{1}{1+n}\left[1-\frac{\varepsilon}{1+\delta}\right]$

La expresión (10) define las ventas de equilibrio de cada traficante. Esta solución en la segunda etapa del juego corresponde exactamente a la del modelo de Raffo (2015). A medida que aumenta el número de traficantes, $n$, la participación de las ventas de cada traficante es menor, lo cual genera barreras de entrada o contiendas entre traficantes. Igualmente, a medida que aumenta la sanción unitaria esperada, $\varepsilon$, ceteris paribus, las ventas de cada traficante son menores, $q_{i}^{*}$, lo cual se explica por el aumento de los costos esperados marginales y totales de represión. Sin embargo, este resultado debe ser analizado desde las ventas agregadas para determinar el efecto total de la represión en el mercado.

\footnotetext{
${ }^{11} q_{-i}$ es el vector de unidades de drogas ilícitas vendidas por traficantes dis-
} tintos de $i$. 
Dado que $Q=\sum_{i=1}^{n} q_{i}$ y $q^{*}=q_{1}^{*}=\cdots=q_{n}^{*}$ (equilibrio simétrico de Nash), las ventas agregadas vienen dadas por:

$Q^{*}(\varepsilon, n, \delta)=\frac{n}{1+n}\left[1-\frac{\varepsilon}{1+\delta}\right]$

En primera instancia, (10) y (11) develan que existirá un mercado ilegal de drogas ilícitas (transacciones factibles) si y solo si:

$\varepsilon<(1+\delta)$

Existe entonces un umbral máximo $(1+\delta)$ a partir del cual no es factible ninguna transacción de drogas ilícitas, ya que una multa unitaria esperada superior a dicho umbral supera las posibilidades reales del mercado ilegal. Según Poret y Téjedo (2006) y Raffo (2015), este umbral máximo $(1+\delta)$ no se alcanza en la realidad, ya que llevaría a un desbordamiento de los costos de vigilar y castigar por parte del Estado a las bandas criminales, lo cual hace posible cumplir la condición (12).

De (10) se obtiene que ante aumentos de $\varepsilon$ disminuye $q_{i}^{*}$, lo cual se hace extensivo a las ventas agregadas de drogas $Q^{*}[\operatorname{ver}(11)]$. Esto puede servir de sustento para la focalización de la represión como principal o único mecanismo de desarticulación de redes criminales que transan drogas ilícitas. Sin embargo, como se aprecia en (12), existe un umbral de costos por sanción (o represión) que hace inviable la completa desarticulación de dichos mercados por la mera fuerza de la represión. Además, como sustenta la tesis del presente trabajo, las estructuras criminales generan procesos adaptativos sobre dicha represión, que terminan subvirtiendo el proceso de represión estatal con mecanismos cada vez más complejos para la permanencia de las transacciones de drogas ilegales.

De (11) se evidencia que un incremento en el número de agentes traficantes (bandas criminales para este caso), ceteris paribus, conduce a un aumento de las transacciones totales del mercado ( $Q$ ). Según Raffo (2015), esto es un efecto de incrementos en la competencia. Sin embargo, al aumentar $n$, las transacciones efectivas de cada traficante $i$ se reducen [ver (10)], principalmente porque al aumentar la competencia se reducen los precios y el ingreso marginal de los traficantes, lo que en últimas conduce a una reducción de transacciones efectivas por traficante. A pesar de lo anterior, el efecto agregado de aumento de $n$ es mayor que el efecto individual de reducción de $q_{i}^{*}$, lo cual genera un aumento en las ventas agregadas del mercado.

Desde el punto de vista de la estructura en red de las bandas criminales se puede plantear, según los resultados, que un incremento en la densidad media de la red genera un aumento en las transacciones 
efectivas agregadas de drogas ilegales (y viceversa). El aumento de la densidad media en $g, \delta /(n-1)$, genera un incremento de las conexiones directas de cada traficante, aumentando el grado medio $\delta$ de los agentes en la red $g$. Lo anterior genera un efecto de retroalimentación positiva, es decir, la retribución de realizar una acción aumenta con el número de personas que realizan la misma acción; en este caso traficar drogar ilícitas en $g$. Estas externalidades de red, impulsadas por la articulación de la red, reducen la PDA, lo cual hace reducir los costos esperados por el acto ilegal, generando incentivos para el incremento de transacciones ilegales efectivas en términos agregados ${ }^{12}$. Como señala Raffo $(2015,82)$, "al crecer $\delta$ bajan los costos esperados de represión que enfrenta cada traficante, por lo que cada uno tiene incentivos para vender más".

De (6) tenemos que $P^{*}(\varepsilon, n, \delta)=1-Q^{*}$; por lo tanto:

$P^{*}(\varepsilon, n, \delta)=1-\frac{n}{1+n}\left[1-\frac{\varepsilon}{1+\delta}\right]$

La expresión (13) define el precio de equilibrio del mercado en función de las variables estratégicas de interacción del mercado de drogas ilícitas según el modelo propuesto. Si se cumple (12), esta expresión siempre genera valores positivos, lo cual es una condición básica para la existencia de incentivos económicos. Según la expresión (13), dados los valores para $\delta$ y $n$, si aumenta la represión contra las drogas, es decir, si aumenta la sanción unitaria esperada, $\varepsilon$, es de esperar un aumento del nivel de precios de equilibrio del mercado de drogas ilícitas. Esta tesis es un sustento frecuente de las autoridades de control para reforzar la represión contra la oferta, ya que incrementos progresivos de la represión -vía detección, arresto y sanción de traficantes- elevan el precio a tal nivel que se logra reducir (o evitar) el consumo de drogas. En contraste con la evidencia teórico-analítica anterior, Raffo (2015) muestra que en las últimas tres décadas los precios de las drogas duras (cocaína y heroína) han tendido a la baja; a pesar de rigurosas políticas de represión de la oferta en los órdenes local, nacional e internacional. Este proceso, contrario al sustento teórico, se debe a las continuas transformaciones de las redes criminales que se han adaptado de forma racional y estratégica a los procesos de represión, definiendo estructuras en red cada vez más cohesionadas, articuladas y densas; lo cual permite reducir los precios a niveles de sostenibilidad del mercado. Esto se aprecia en la misma expresión (13), ya que, dados los valores de $n$ y $\varepsilon$, un aumento en la densidad media

12 Esto se deduce de $f(\varphi, \delta)=\frac{\varphi}{1+\delta}$, ecuación (7). 
de la red reduce el precio de equilibrio. Por tal razón, a partir de (13) se puede probar que los precios son una función convexa decreciente de $\delta$ (gráfica 1 ).

\section{Gráfica 1}

Precio de equilibrio de Nash de las drogas en función $\delta$ en la segunda etapa

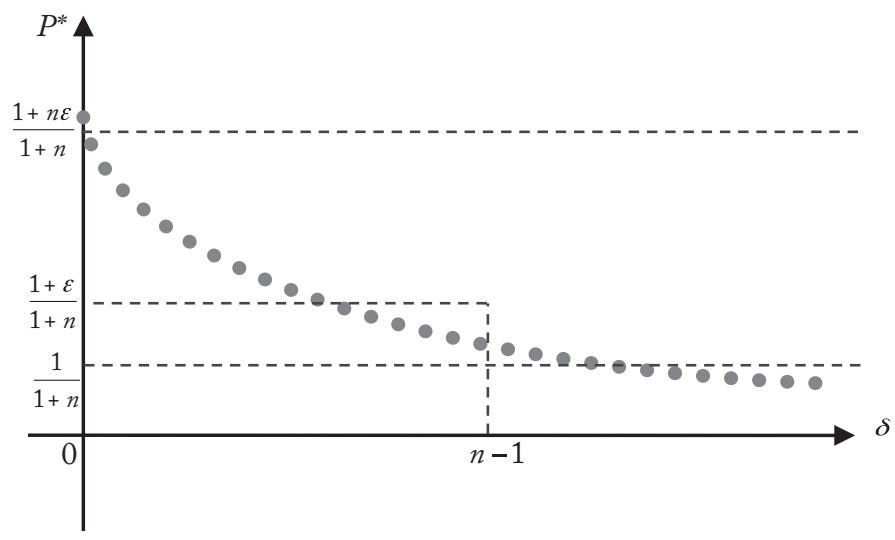

Fuente: elaboración propia.

Así mismo, se puede probar que, ceteris paribus, mayores niveles de $n$ llevan a bajas de precios; en efecto, se puede probar que los precios también son una función convexa en $n$ (gráfica 2).

Gráfica 2

Precio de equilibrio de Nash de las drogas en función de $n$ en la segunda etapa

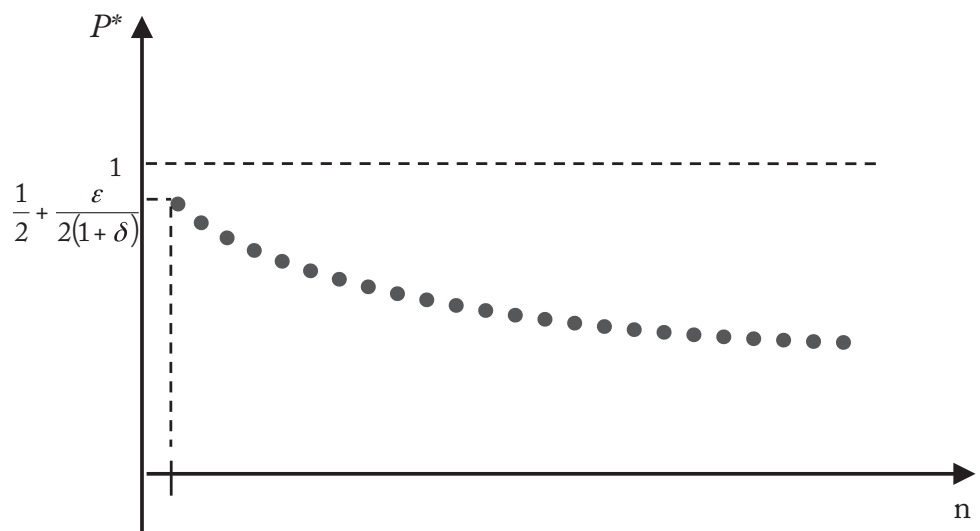

Fuente: elaboración propia. 
Por último, sustituyendo (10) y (13) en la función de ganancias esperadas se obtiene:

$$
\pi^{*}\left(\varepsilon, n, \delta, \widetilde{c_{l}}\right)=\frac{1}{(1+n)^{2}}\left[1-\frac{\varepsilon}{1+\delta}\right]^{2}-\eta \widetilde{c_{l}}
$$

Raffo (2015) analiza una expresión análoga. Para esta etapa del juego eso se obvia aquí por limitaciones de espacio.

\section{SOLUCIÓN DE LA PRIMERA ETAPA}

En esta etapa se desarrolla la contienda entre autoridades $(G)$ y bacrim $\left(c_{i}\right)$, lo cual define la probabilidad de detectar una transacción (actividad) ilegal ( $\varphi$ ), que establece el nivel de cooptación del territorio por parte de los agentes en contienda. Esta probabilidad $\varphi$ tiene un carácter diferencial en el territorio, tal como sucede en la realidad, lo cual permitiría analizar la espacialidad de dicha probabilidad en zonas geográficas específicas. Además, la probabilidad no es constante en el tiempo, ya que en ella influyen las coyunturas de la contienda por el poder territorial. Dado el carácter teórico-analítico de este trabajo, tal consideración desborda el análisis.

La probabilidad de detectar una transacción ilegal, $\varphi$, es en esencia un juego de poder, de correlación de fuerzas entre dos agentes contrarios que - a través de distintos mecanismos de control y orden por parte de las autoridades, y disuasivos (de la fuerza bruta a la compra de silencio) de las bandas criminales- definen los niveles de cooptación del territorio, los cuales permiten distintos niveles de criminalidad en función de dicha contienda. Lo interesante es que el poder territorial de las bandas criminales va mucho más allá del poder sobre el suelo; es un poder legitimado por la estructura social (en mayor o menor grado según el nivel de marginalización social), por ciertos sectores de las autoridades de control y por algunas altas esferas del poder político. El poder territorial o cooptación del territorio debe entenderse como el resultado de la interacción de múltiples fuerzas sociales en un proceso continuo que define dominados, dominadores y condiciones de dominación.

Cuando las bandas criminales cooptan el territorio no solo se gesta la posibilidad de producir, distribuir o comercializar drogas ilícitas; además es posible reconfigurar la estructura social del territorio para reproducir las actividades ilegales, lo que en algunos casos es la principal alternativa para entrar en mercados de grandes masas sociales. En este espacio la criminalidad obtiene legitimidad social y, con ello, la cooptación del territorio. Duncan $(2014,100)$ afirma que "el punto 
de quiebre en el proceso de producción de poder desde el narcotráfico ocurre cuando -debido a la magnitud de las transformaciones sociales- la regulación de actividades puramente criminales se extiende a la regulación de la sociedad".

Esto es interesante porque hace más costosa la lucha contra las bandas criminales. El éxito político de las bandas criminales no solo consiste en la toma de decisiones de poder según sus beneficios, sino en la ausencia de decisiones en su contra como consecuencia de la resistencia social a estas decisiones. La cooptación del territorio por parte de las bandas criminales le apunta precisamente a esta estrategia, articular sus intereses con los de la comunidad donde se asienta, ya que esto transciende la actividad económica ilegal hacia una transformación social de comunidades marginalizadas. Este proceso se da por las buenas o por las malas, ya que cuando las comunidades no son receptivas a las actividades ilegales que se realizan en su territorio son cooptadas por la intimidación a través de submercados o actos ilegales como los ya mencionados, que buscan marcar el territorio, además de diversificar el riesgo y los ingresos de las bandas criminales (Holland, 2013).

Definido lo anterior, de (1) tenemos que la probabilidad de detectar una transacción ilegal está dada por $\varphi=G\left(1-\tilde{c}_{i}\right)$. Y de (1) y (10) las ventas de equilibrio de cada traficante se expresan así:

$q^{*}\left(s, \widetilde{c_{l}}, n, \delta\right)=\frac{1}{1+n}\left[1-\frac{s G\left(1-\widetilde{c_{2}}\right)}{1+\delta}\right]$

Y puesto que $\varphi=G\left(1-\widetilde{c_{l}}\right)$ depende de $\widetilde{c_{l}}$, esta expresión corresponde a la función de reacción de los distribuidores de drogas al por menor en la segunda etapa del juego con respecto a esta variable, la cual es determinada en la primera etapa por las elecciones de corrupción de los traficantes. Esta función de reacción revela que al aumentar los niveles de corrupción en la primera etapa del juego crecen las ventas de drogas en la segunda etapa. Obsérvese que:

$$
\frac{\partial q^{*}\left(s, \widetilde{l_{l}}, n, \delta\right)^{*}}{\partial \widetilde{c_{l}}}=\frac{s G}{(1+n)(1+\delta)}
$$

El problema que resuelven los traficantes en la primera etapa, teniendo como variable objetivo el esfuerzo, en términos monetarios, por controlar el territorio, $\widetilde{c_{l}}$, es:

$$
\operatorname{Max} \pi_{i}\left(q_{i}^{*}, q_{-i}^{*}, \widetilde{c_{l}} s, \varphi, \delta\right)=\left(1-q_{i}^{*}-\sum_{j \neq i} q_{j}^{*}\right) q_{i}^{*}-\frac{s \varphi}{1+\delta} q_{i}^{*}-\eta \widetilde{c_{l}}
$$


Considerando que las bacrim en cabeza de los traficantes conocen las funciones de reacción de los distribuidores al por menor en la segunda etapa, así como el equilibrio simétrico de Nash perfecto de subjuego en esa etapa, su problema de elección con respecto a $\widetilde{c_{l}}$, utilizando (1) y (10), corresponde a:

$$
\operatorname{Max} \pi_{i}\left(q^{*}, s, \varphi, \delta\right)=\left[1-\frac{n}{1+n}\left(1-\frac{s \varphi}{1+\delta}\right)-\frac{s \varphi}{1+\delta}\right]\left[\frac{1}{1+n}\left(1-\frac{s \varphi}{1+\delta}\right)\right]-\eta \widetilde{c_{l}}
$$

Luego de algunas operaciones algebraicas se llega a:

$$
\operatorname{Max} \pi_{i}\left(q^{*}, s, \varphi, \delta\right)=\frac{1}{1+n}-\frac{n}{(1+n)^{2}}-\frac{2 s G}{(1+n)^{2}(1+\delta)}\left(1-\widetilde{c_{l}}\right)+\frac{s^{2} G^{2}}{(1+n)^{2}(1+\delta)^{2}}\left(1-\widetilde{c_{l}}\right)^{2}-\eta \widetilde{c_{l}}
$$

La condición de primer orden $\left[\frac{\partial \pi_{i}(\cdot)}{\partial \widetilde{c}_{l}}=0\right]$ viene dada por:

$$
\frac{2 s G}{(1+n)^{2}(1+\delta)}-\frac{2 s^{2} G^{2}}{(1+n)^{2}(1+\delta)^{2}}\left(1-\widetilde{c_{l}}\right)-\eta=0
$$

Al despejar $\widetilde{c_{l}}$ se obtiene:

$\widetilde{c_{l}^{*}}=1-\frac{(1+\delta)}{\tilde{\varepsilon}}\left[1-\frac{(1+n)^{2}(1+\delta)}{2 \tilde{\varepsilon}} \eta\right]$

donde $\widetilde{\varepsilon}=s G$ corresponde a un índice de represión conjunta que tiene en cuenta los recursos que las autoridades de control invierten para controlar el territorio, así como el parámetro $s$; además, $0<\widetilde{c_{i}^{*}}<1$; por lo tanto, $\frac{(1+n)^{2}(1+\delta)}{2 s G} \eta<1$. Esto se cumple cuando $s G>\frac{(1+n)^{2}(1+\delta)}{2} \eta$; lo cual tiene sentido ya que la corrupción es estratégica para la criminalidad ante una alta represión por parte de las autoridades de control.

El nivel óptimo de recursos (monetarios) que destinan las bandas criminales al desarrollo de la contienda depende de cuatro variables en la perdurabilidad y rentabilidad del negocio: 1) el índice de represión conjunta $(s G) ; 2$ ) el número de bandas criminales (o traficantes) (n);3) el grado medio de los agentes en la red (8), y 4) el costo marginal de corrupción ( $\eta$ ). A continuación se presentan los resultados de estática comparativa para definir la relación de dichas variables con el nivel de corrupción óptimo de las bandas criminales.

El cuadro 1 presenta las relaciones del nivel óptimo de recursos (monetarios) que destinan las bandas criminales al desarrollo de la contienda $\left(\widetilde{c_{l}^{*}}\right)$ con cada una de las variables antes mencionadas. Los resultados indican que la estructura de la red criminal, su grado de densificación y el número de bandas criminales (o traficantes) determinan los gastos de corrupción que realizan los traficantes. 
En primer lugar se observa que si $s G>(1+n)^{2}(1+\delta) \eta$, ante incrementos de la multa $s$, ceteris paribus, la asignación de recursos para la contienda es mayor (aumenta $\widetilde{c_{l}^{*}}$ ); es decir, la multa como represión de la oferta puede tener un efecto contraproducente para altos niveles de represión, captados por $s G$; en tal caso, incrementos en estas propician aumentos en la tarifa de corrupción que eventualmente pueden exigir las autoridades de control corruptas sobre las bandas criminales existentes. No obstante, lo contrario sucede para bajos niveles de corrupción, $s G<(1+n)^{2}(1+\delta) \eta$.

Por otro lado, a medida que aumenta el valor de los recursos por parte de las autoridades de control $(G)$ para combatir las bandas criminales, se incrementa el valor de los recursos que los traficantes invierten en corrupción, cuando $s G>(1+n)^{2}(1+\delta) \eta$. Lo contrario sucede si $s G>(1+n)^{2}(1+\delta) \eta$.

Cuadro 1

Estática comparativa: nivel de corrupción óptimo de las bacrim $\left(\widetilde{c_{i}}\right)$

\begin{tabular}{|c|c|c|}
\hline $\begin{array}{l}\text { Condición } \\
\text { de cambio }\end{array}$ & Resultado & Relación \\
\hline$\frac{\partial \widetilde{c_{l}^{*}}(\cdot)}{\partial s}$ & $\begin{array}{l}\frac{(1+\delta)}{s^{2} G}\left(1-\frac{(1+n)^{2}(1+\delta)^{2}}{s G} \eta\right) \text {, donde, } 0<G<1 \text { y } \delta, n \text {, } s \text { y } \eta \in R^{+} \\
\operatorname{Si} \frac{(1+n)^{2}(1+\delta)}{s G} \eta>1 \text {, es decir, cuando } \\
(1+n)^{2}(1+\delta)^{2} \eta>s G \text {; se define una relación negativa }\end{array}$ & $\begin{array}{l}\text { Negativa } \\
s G<(1+n)^{2}(1+\delta) \eta \\
\uparrow s \text {, entonces } \downarrow \widetilde{c_{l}^{*}} \\
\downarrow s \text {, entonces } \uparrow \widetilde{c_{l}^{*}} \\
\text { Positiva } \\
s G>(1+n)^{2}(1+\delta) \eta \\
\uparrow s \text {, entonces } \uparrow \widetilde{c_{l}^{*}} \\
\downarrow s \text {, entonces } \downarrow \widetilde{c_{l}^{*}}\end{array}$ \\
\hline$\frac{\partial \widetilde{c_{l}^{*}}(\cdot)}{\partial G}$ & $\begin{array}{l}\frac{(1+\delta)}{s G^{2}}\left(1-\frac{(1+n)^{2}(1+\delta)}{s G} \eta\right) \text {, donde } 0<G<1 \text { y } \delta, n \text {, } s \text { y } \eta \in R^{+} \\
\mathrm{Si} \frac{(1+n)^{2}(1+\delta)}{s G} \eta>1 ; \text { es decir, cuando } \\
(1+n)^{2}(1+\delta) \eta>s G \text { se define una relación negativa }\end{array}$ & $\begin{array}{l}\text { Negativa } \\
s G<(1+n)^{2}(1+\delta) \eta \\
\uparrow G \text {, entonces } \downarrow \widetilde{c_{l}^{*}} \\
\downarrow G, \text { entonces } \uparrow \widetilde{c_{l}^{*}} \\
\text { Positiva } \\
s G>(1+n)^{2}(1+\delta) \eta \\
\uparrow G \text {, entonces } \uparrow \widetilde{c_{l}^{*}} \\
\downarrow G \text {, entonces } \downarrow \widetilde{c_{l}^{*}}\end{array}$ \\
\hline$\frac{\partial \widetilde{c_{l}^{*}}(\cdot)}{\partial n}$ & $\frac{(1+n)(1+\delta)^{2}}{s^{2} G^{2}} \eta$, donde $0<G<1$ y $\delta$, n, s y $\eta \in R^{+}$ & $\begin{array}{l}\text { Positiva } \\
\uparrow n \text {, entonces } \uparrow \widetilde{c_{l}^{*}} \\
\downarrow n \text {, entonces } \downarrow \widetilde{c_{l}^{*}}\end{array}$ \\
\hline$\frac{\partial \widetilde{c_{l}^{*}}(\cdot)}{\partial \delta}$ & $\begin{array}{l}-\frac{1}{s G}+\frac{(1+n)^{2}(1+\delta)}{s^{2} G^{2}} \eta, \text { donde } 0<G<1 \text { y } \delta, n \text {, s y } \eta \in R^{+} \\
\mathrm{Si}-\frac{1}{s G}>\frac{(1+n)^{2}(1+\delta)}{s^{2} G^{2}} \eta \text {, es decir, cuando } \\
s G \lesseqgtr(1+n)^{2}(1+\delta) \eta\end{array}$ & $\begin{array}{l}\text { Negativa } \\
s G>(1+n)^{2}(1+\delta) \eta \\
\uparrow \delta \text {, entonces } \downarrow \widetilde{c_{\iota}^{*}} \\
\downarrow \delta \text {, entonces } \uparrow \widetilde{c_{l}^{*}} \\
\text { Positiva } \\
s G<(1+n)^{2}(1+\delta) \eta \\
\uparrow \delta \text {, entonces } \uparrow \widetilde{c_{l}^{*}} \\
\downarrow \delta \text {, entonces } \downarrow \widetilde{c_{l}^{*}} \\
\end{array}$ \\
\hline$\frac{\partial \widetilde{c_{l}^{*}}(\cdot)}{\partial \eta}$ & $\frac{(1+n)^{2}(1+\delta)^{2}}{2 s^{2} G^{2}}$, donde $0<G<1$ y $\delta$, $n$, s y $\eta \in R^{+}$ & $\begin{array}{l}\text { Positiva } \\
\uparrow \eta \text {, entonces } \uparrow \widetilde{c_{l}^{*}} \\
\downarrow \eta \text {, entonces } \downarrow \widetilde{c_{l}^{*}}\end{array}$ \\
\hline
\end{tabular}

Fuente: elaboración propia. 
Estos dos resultados revelan que un endurecimiento de las políticas de represión, bien sean mayores multas o mayores gastos para combatir la corrupción, pueden llevar a que los agentes reaccionen estratégicamente e inviertan más recursos en corrupción.

Siguiendo con el análisis, ante incrementos del número de bandas criminales (o traficantes), ceteris paribus, se obtienen aumentos en el nivel de recursos de dichas bandas para el desarrollo de la actividad criminal, lo cual puede entenderse como un efecto competencia, donde a mayor competencia entre bandas, los aportes para el combate o pagos corruptos a las autoridades de control se hacen mayores. Esto evidencia la necesidad de cooptar territorios; es decir, la apropiación de territorios con cierta legitimidad social, voluntaria o forzada por el terror, permite definir procesos de demarcación de espacios no conducentes a competencia, algo como fronteras invisibles de producción, distribución y comercialización.

Por último, al incrementarse el grado medio de los agentes en la red $(\delta)$, si $s G>(1+n)^{2}(1+\delta) \eta$, se reduce el aporte de recursos destinados a la corrupción $\left(\widetilde{c_{l}^{*}}\right)$. Esto puede entenderse por el menor éxito de la represión en presencia de incrementos en el grado medio de los agentes $y$, por ende, en la densidad media de las redes: a medida que esto sucede, se tienden a generar sinergias criminales que en términos marginales reducen los montos de inversión en corrupción requeridos por cada agente criminal para maximizar sus ganancias. Lo contrario sucedería si $s G<(1+n)^{2}(1+\delta) \eta$.

Reemplazando (15) en (1) se obtiene:

$\varphi^{*}=\frac{(1+\delta)}{s}\left(1-\frac{(1+n)^{2}(1+\delta)}{2 s G} \eta\right)$

En el mismo sentido, la probabilidad de detectar una transacción ilegal depende de las cuatro variables mencionadas en (15). El cuadro 2 presenta los resultados de estática comparativa para definir la relación de dichas variables con la probabilidad de detectar una transacción ilegal, esencia de la perdurabilidad del mercado de sustancias ilícitas en el tiempo.

Cambios en el nivel de recursos por parte de las autoridades de control $(G)$, ceteris paribus, generan una relación positiva con dicha probabilidad, lo cual es lógico, ya que incrementos en el valor de los recursos, que se traduce en mayor represión, deben aumentar la probabilidad de detectar transacciones en dicho mercado ilegal, y viceversa. También se encontró que ante cambios en el número de bandas criminales (o traficantes) $(n)$, ceteris paribus, se genera una relación negativa con dicha probabilidad. 
Cuadro 2

Estática comparativa: probabilidad de detectar una transacción ilegal $(\varphi *)$

\begin{tabular}{|c|c|c|}
\hline $\begin{array}{l}\text { Condición } \\
\text { de cambio }\end{array}$ & Resultado & Relación \\
\hline$\frac{\partial \varphi^{*}(\cdot)}{\partial s}$ & $\begin{array}{l}-\frac{(1+\delta)}{s^{2}}+\frac{(1+n)^{2}(1+\delta)^{2}}{s^{3} G} \eta, \text { donde } 0<G<1 \text { y } \delta, n \text {, s y } \eta \in R^{+} \\
\mathrm{Si}-\frac{(1+\delta)}{s^{2}}>\frac{(1+n)^{2}(1+\delta)^{2}}{s^{3} G} \eta ; \text { es decir, cuando } s G \gtreqless \\
(1+n)^{2}(1+\delta) \eta\end{array}$ & $\begin{array}{l}\text { Negativa } \\
s G>(1+n)^{2}(1+\delta) \eta \\
\uparrow s \text {, entonces } \downarrow \varphi^{*} \\
\downarrow s \text {, entonces } \uparrow \varphi^{*} \\
\text { Positiva } \\
s G<(1+n)^{2}(1+\delta) \eta \\
\uparrow s \text {, entonces } \uparrow \varphi^{*} \\
\downarrow s \text {, entonces } \downarrow \varphi^{*}\end{array}$ \\
\hline$\frac{\partial \varphi^{*}(\cdot)}{\partial G}$ & $\frac{(1+n)^{2}(1+\delta)^{2}}{2 s^{2} G^{2}} \eta$, donde $0<G<1$ y $\delta, n$, s y $\eta \in R^{+}$ & $\begin{array}{l}\text { Positiva } \\
\uparrow G \text {, entonces } \uparrow \varphi^{*} \\
\downarrow G \text {, entonces } \downarrow \varphi^{*}\end{array}$ \\
\hline$\frac{\partial \varphi^{*}(\cdot)}{\partial n}$ & $-\frac{(1+n)(1+\delta)^{2}}{s^{2} G} \eta$, donde $0<G<1$ y $\delta, n$, s y $\eta \in R^{+}$ & $\begin{array}{l}\text { Negativa } \\
\uparrow n \text {, entonces } \downarrow \varphi^{*} \\
\downarrow n \text {, entonces } \uparrow \varphi^{*}\end{array}$ \\
\hline$\frac{\partial \varphi^{*}(\cdot)}{\partial \delta}$ & $\begin{array}{l}\frac{1}{s}-\frac{(1+n)^{2}(1+\delta)}{s^{2} G} \eta, \text { donde } 0<G<1 \text { y } \delta, n \text {, s y } \eta \in R^{+} \\
\text {Si } \frac{1}{s}>\frac{(1+n)^{2}(1+\delta)}{s^{2} G} \eta \text {; es decir, cuando } \\
s G \gtreqless(1+n)^{2}(1+\delta) \eta\end{array}$ & $\begin{array}{l}\text { Positiva } s G<(1+ \\
n)^{2}(1+\delta) \eta \\
\uparrow \delta \text {, entonces } \uparrow \varphi^{*} \\
\downarrow \delta \text {, entonces } \downarrow \varphi^{*} \\
\text { Negativa } s G> \\
(1+n)^{2}(1+\delta) \eta \\
\uparrow \delta \text {, entonces } \downarrow \varphi^{*} \\
\downarrow \delta \text {, entonces } \uparrow \varphi^{*}\end{array}$ \\
\hline$\frac{\partial \varphi^{*}(\cdot)}{\partial \eta}$ & $-\frac{(1+n)^{2}(1+\delta)^{2}}{2 s^{2} G}$, donde $0<G<1$ y $\delta$, n, s y $\eta \in R^{+}$ & $\begin{array}{l}\text { Negativa } \\
\uparrow \eta \text {, entonces } \downarrow \varphi^{*} \\
\downarrow \eta \text {, entonces } \uparrow \varphi^{*} \\
\end{array}$ \\
\hline
\end{tabular}

Fuente: elaboración propia.

Esto puede suceder por expansión de las transacciones criminales que en términos marginales afectan el éxito de la represión, lo cual reduce la probabilidad; y además, en redes regulares, donde la centralidad de grado de todos los traficantes es igual, no se generan efectos de visibilización de algunos actores específicos, definiendo mayor complejidad para las autoridades de control en caracterizar y capturar a los agentes ilegales. Esto tiene sentido en la realidad, pues existe un alto número de agentes dedicados al microtráfico de drogas y al narcomenudeo, y la mayor parte de ellos tienden a actuar con un bajo perfil. Por esto el modelo con redes regulares es relevante.

Ahora bien, la multa $(s)$ y el grado medio de los agentes en la red

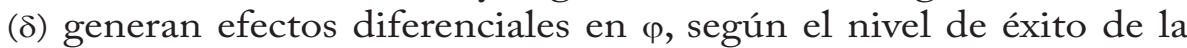
represión. En el caso de la multa $(s)$, si $s G>(1+n)^{2}(1+\delta) \eta$, se genera una relación negativa; es decir, ante aumentos de la multa, en un escenario de alta represión conjunta, se reduce la probabilidad de detectar una transacción ilegal, sobre todo por el efecto corrupción, ya que el aumento de la multa solo elevaría la cuota de corrupción, con efectos contrarios en la detección de actividades ilegales. 
Ese efecto indica que la alta represión genera incentivos perversos para los agentes corruptos, y desvirtúa, desde las mismas autoridades de control, el objetivo de la política criminal. Por el contrario, si $s G<(1+n)^{2}(1+\delta) \eta$, se genera una relación positiva; es decir, aumentos de la represión -vía multa- aumentan la probabilidad de detectar transacciones de drogas ilegales. Esto muestra lo complejo que es para las autoridades de control definir los mecanismos y el nivel óptimo de represión, pues una represión desbordada genera incentivos para criminalizar a ciertos miembros de esas autoridades.

Por último, si $s G>(1+n)^{2}(1+\delta) \eta$, se genera una relación positiva entre el grado medio de los agentes en la red ( $\delta)$ y la probabilidad de detectar una transacción de drogas ilícitas $(\varphi)$. Aunque la densidad de la red aumente, y con ello las sinergias criminales, en momentos de alto impacto de la represión, la probabilidad de detección aumenta, condicionando el resultado anterior del efecto expansión de la red. Esto hace necesario el establecimiento de barreras de entrada y grados de especialización en dicho mercado, para evitar una visibilidad de la red como un todo, demandando un comportamiento estratégico por parte de las bandas criminales (o traficantes). Por el contrario, si $s G<(1+n)^{2}(1+\delta) \eta$, la relación entre $\delta$ y $\varphi$ es negativa; es decir, aumentos en la densidad de la red generan un impacto negativo en la probabilidad de detectar transacciones ilegales, cuando el nivel de represión conjunta es bajo, lo cual se explica por las sinergias criminales analizadas anteriormente.

Cuadro 3

Estática comparativa: nivel de transacciones de un traficante

\begin{tabular}{|c|c|c|}
\hline Condición de cambio & Resultado & Relación \\
\hline$\frac{\partial q^{*}(\cdot)}{\partial n}$ & $\frac{(1+\delta)}{2 s G} \eta$, donde $0<G<1$ y $\delta, n, s$ y $\eta \in R^{+}$ & $\begin{array}{l}\text { Positiva } \\
\uparrow n, \text { entonces, } \uparrow q^{*} \\
\downarrow n, \text { entonces }, \downarrow q^{*}\end{array}$ \\
\hline$\frac{\partial q^{*}(\cdot)}{\partial \eta}$ & $\frac{(1+n)(1+\delta)}{2 s G}$, donde $0<G<1$ y $\delta, n$, s y $\eta \in R^{+}$ & $\begin{array}{l}\text { Positiva } \\
\uparrow \eta, \text { entonces, } \uparrow q^{*} \\
\downarrow \eta, \text { entonces }, \downarrow q^{*}\end{array}$ \\
\hline$\frac{\partial q^{*}(\cdot)}{\partial s}$ & $-\frac{(1+n)(1+\delta)}{2 s^{2} G} \eta$, donde $0<G<1$ y $\delta, n$, s $y \eta \in R^{+}$ & $\begin{array}{l}\text { Negativa } \\
\uparrow s, \text { entonces, } \downarrow q^{*} \\
\downarrow s, \text { entonces }, \uparrow q^{*}\end{array}$ \\
\hline$\frac{\partial q^{*}(\cdot)}{\partial G}$ & $-\frac{(1+n)(1+\delta)}{2 s G^{2}} \eta$, donde $0<G<1$ y $\delta, n$, s y $\eta \in R^{+}$ & $\begin{array}{l}\text { Negativa } \\
\uparrow G, \text { entonces, } \downarrow q^{*} \\
\downarrow G, \text { entonces }, \uparrow q^{*}\end{array}$ \\
\hline$\frac{\partial q^{*}(\cdot)}{\partial \delta}$ & $\frac{(1+n)}{2 s G} \eta$, donde $0<G<1$ y $\delta, n$, s y $\eta \in R^{+}$ & $\begin{array}{l}\text { Positiva } \\
\uparrow \delta, \text { entonces }, \uparrow q^{*} \\
\downarrow \delta, \text { entonces }, \downarrow q^{*}\end{array}$ \\
\hline
\end{tabular}

Fuente: elaboración propia. 
El modelo capta el comportamiento interdependiente y estratégico entre autoridades de control y bandas criminales (o traficantes). Esto se muestra en la condición $s G \gtreqless(1+n)^{2}(1+\delta) \eta$, ya que dependiendo de su fuerza relacional se generan procesos de aumento o disminución de la actividad criminal, y deja en claro que debido al comportamiento estratégico que la represión de la oferta induce sobre las bandas criminales (o traficantes), la capacidad de adaptación de las bandas alcanza su mayor expresión, y se encamina hacia la cooptación de territorios con la aparición de submercados ilegales que concretan tal propósito, y además reducen el costo marginal de la corrupción $(\eta)$.

En la segunda etapa se obtuvo el nivel de transacciones óptimas por traficante, $q^{*}=\frac{1}{1+n}\left[1-\frac{s \varphi^{*}}{1+\delta}\right]$; sustituyendo $\varphi^{*}$ (probabilidad de equilibrio de detectar una transacción ilegal) en $q^{*}$ se obtiene:

$q^{*}=\frac{(1+n)(1+\delta)}{2 s G} \eta$

E1 nivel de transacciones de equilibrio de Nash perfecto de subjuego de un traficante depende de las variables estratégicas del modelo, las cuales definen las siguientes relaciones de comportamiento.

A nivel agregado se definió el nivel de transacciones óptimas del mercado, $Q^{*}$. Al sustituir en dicha expresión la probabilidad óptima de detectar una transacción ilegal se obtiene:

$Q^{*}=\frac{n(1+n)(1+\delta)}{2 s G} \eta$

En forma análoga, la expresión (17) depende de los parámetros del modelo. Nótese que:

$\frac{\partial Q^{*}(\cdot)}{\partial n}=\frac{(1+\delta)}{2 s G} \eta(1+2 n)>0$

Dado que $P^{*}=1-Q^{*}$, debe cumplirse que $Q^{*}=\frac{n(1+n)(1+\delta)}{2 s G} \eta<1$, es decir, $2 s G>n(1+n)(1+\delta) \eta$.

Sustituyendo la probabilidad óptima de detectar una transacción ilegal en el precio de mercado, se obtiene:

$P^{*}=1-\frac{n(1+n)(1+\delta)}{2 s G} \eta$

E1 cuadro 4 presenta la estática comparativa de la expresión (18).

Por último, se puede probar que, en la segunda etapa, $\pi^{*}=q^{* 2}$; así se obtiene:

$\pi^{*}=\frac{(1+n)^{2}(1+\delta)^{2}}{4 s^{2} G^{2}} \eta^{2}$

Todos los parámetros influyen en $\pi^{*}$, de igual manera que en $q^{*}$. 
Cuadro 4

Estática comparativa del precio de mercado

\begin{tabular}{lll}
\hline Condición de cambio & \multicolumn{1}{c}{ Resultado } & Relación \\
\hline$\frac{\partial P^{*}(\cdot)}{\partial n}$ & $-\frac{(1+\delta)}{2 s G} \eta(1+2 n)$, donde $0<G<1 \mathrm{y} \delta, n, s y \eta \in R^{+}$ & Negativa \\
\hline$\frac{\partial P^{*}(\cdot)}{\partial \eta}$ & $-\frac{n(1+n)(1+\delta)}{2 s G}$, entonces $\downarrow P^{*}$ \\
& $\downarrow n$, entonces $\uparrow P^{*}$ \\
\hline$\frac{\partial P^{*}(\cdot)}{\partial s}$ & $\frac{n(1+n)(1+\delta)}{2 s^{2} G} \eta$, donde $0<G<1 \mathrm{y} \delta, n, s y \eta \in R^{+}$ & Negativa \\
\hline & & $\downarrow \eta$, entonces $\downarrow P^{*}$ \\
& & Positiva \\
$\frac{\partial P^{*}(\cdot)}{\partial G}$ & $\frac{n(1+n)(1+\delta)}{2 s G^{2}} \eta$, dontonces $\uparrow P^{*}$ \\
\hline & & $\uparrow s, n, s$, entonces $\uparrow P^{*}$ \\
& & s, entonces $\downarrow P^{*}$ \\
\hline$\frac{\partial P^{*}(\cdot)}{\partial \delta}$ & $-\frac{(1+\delta)}{2 s G} \eta(1+2 n)$, donde $0<G<1 \mathrm{y} \delta, n, s$ y $\eta \in R^{+}$ & $\uparrow G$, entonces \\
& & $\uparrow P^{*}$ \\
\hline
\end{tabular}

Fuente: elaboración propia.

La solución completa del modelo en el equilibrio de Nash perfecto de subjuego indica que se mantienen los resultados básicos obtenidos en la segunda etapa y en Raffo (2015). Pero se constatan dos resultados fundamentales: al incluir las estrategias de corrupción se observa que el impacto de las políticas de represión sobre la PDA y las ventas ilegales se debilita, mientras que se magnifica el impacto positivo de un mayor número de agentes ilegales en el mercado $(n)$ y mayores niveles de densidad de las RTD -captado por mayores grados medios ( $\delta$ ) de los agentes- sobre las ventas de drogas y las ganancias de los traficantes. Prueba de ello es que el impacto marginal de incrementos en $n$ o $\delta$ se mantiene constante, de modo que las ventas de drogas crecen en forma lineal al incrementarse estos parámetros. De ahí que los precios de los estupefacientes decrecen ahora a una tasa constante al incrementarse estos parámetros cuando en el modelo se incorporan las estrategias de corrupción (gráficas 3 y 4). 
Gráfica 3

Precio de equilibrio de Nash perfecto de subjuego en función de $n$

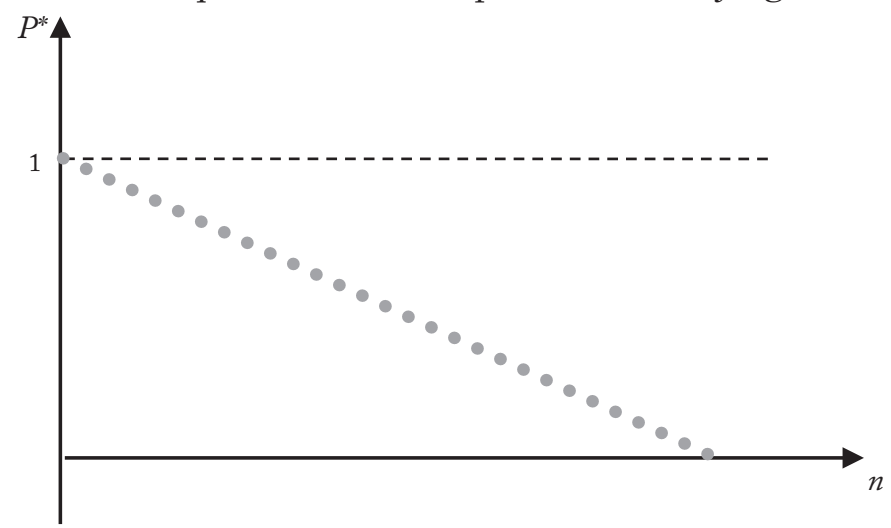

Fuente: elaboración propia.

Gráfica 4

Precio de equilibrio perfecto de subjuego en función de $\delta$

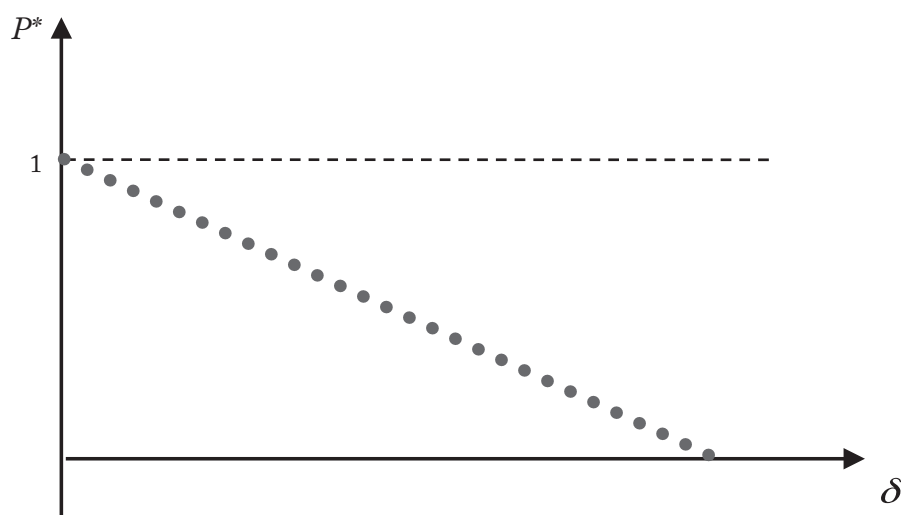

Fuente: elaboración propia.

\section{IMPLICACIONES DEL ANÁLISIS PARA LA POLÍTICA ANTIDROGAS}

La pregunta central que surge del análisis anterior es: ¿por qué las políticas probibicionistas, a pesar de ser equivocadas (según los resultados de las últimas cuatro décadas), no solo perduran, sino que incluso son profundizadas y reciben un amplio apoyo ciudadano, en tanto que las estrategias de legalización regulada o liberalización son de difícil aceptación en el debate público, a pesar de recibir un apoyo creciente de los expertos en el tema? La manera como las autoridades y el Estado asuman este paradigma define la lucha contra las estructuras criminales que trafican drogas ilícitas. 
El problema central del mercado de drogas ilícitas es su ilegalidad, ya que invisibiliza los efectos totales de dicha actividad económica, además de reducir las posibilidades de control frente a la calidad del producto, manejo de excedentes, carga impositiva, etcétera, que subyacen al mercado. La ilegalidad de toda la cadena productiva de drogas ilícitas sobredimensiona socialmente los efectos de esta estructura productiva ilegal. Lo anterior se ve reflejado en el microtráfico y el narcomenudeo, ya que son estrategias adaptativas de las bandas criminales que definen la cooptación del territorio como su principal estrategia de perdurabilidad organizacional. La cooptación del territorio deriva en dos macro resultados: oportunidades económicas para sectores excluidos de la sociedad a través de actividades criminales; y afectación en seguridad para población con algún nivel de inserción a los mercados legales. Ambos resultados son perversos en un estado de derecho y para la seguridad nacional, ya que en el primer caso la criminalidad usurpa el papel del Estado, y en el segundo, las posibilidades reales de acción de la comunidad se ven reducidas por la inseguridad en un territorio específico.

La guerra contra las drogas se ha concentrado excesivamente en la dimensión de la violencia de orden militar, descuidando otros caminos de mayor eficacia para enfrentar esta amenaza a la seguridad nacional. Dos posibles instrumentos que permiten reducir la estrategia de adaptación de las bandas criminales y, con ello, su capacidad de penetración social, son:

1.Perseguir sistemáticamente las finanzas de las bandas criminales, con todos los instrumentos del Estado. Las extraordinarias ganancias, aun a largo plazo, que obtiene el crimen organizado, constituyen el principal instrumento de perdurabilidad y adaptabilidad de dichas organizaciones. Cada fase productiva de drogas ilícitas define tasas de ganancias diferenciales, además de agentes delictivos heterogéneos. La lucha contra las drogas se ha centrado en aquellos agentes que se dedican a la producción de la droga, los cuales pertenecen a la clase que menos ganancias recibe por la actividad económica ilegal, en tanto que los agentes que se dedican a la distribución al por mayor (microtráfico) o al lavado de activos no son objeto de una represión de igual intensidad, siendo estos los que generan mayor tasa de ganancia y con ello los recursos que posibilitan cualquier proceso de adaptabilidad a la represión, y por ende, de perdurabilidad en el negocio.

2. Legalización regulada del consumo de sustancias psicoactivas. Esta estrategia minimiza los efectos negativos del abuso de drogas ilícitas, es decir, convierte el consumo de drogas en un problema de 
salud pública, no en el de orden criminal que ha causado el fracaso de la lucha contra las drogas. Ahora bien, como no se trata de liberalizar el consumo, sino de aceptar las complejidades, en términos de salud pública, que crea el consumo excesivo de dichas sustancias, es necesario abastecer dichos mercados mediante proveedores controlados y arrebatar el monopolio de la distribución a las bandas criminales. Es decir, admitir la existencia de canales de producción y distribución legalizados, controlados por el Estado. Este control debe ser diferencial, según el tipo de efectos y dependencias que provoque cada tipo de sustancia.

Dado el perjuicio de la salud pública que genera el consumo de sustancias ilícitas, el Estado debe elaborar estrategias para desestimularlo, principalmente en dos frentes: 1) las redes de distribución legal no podrán incentivar, vía estrategias de mercadeo, el consumo de dichas sustancias, y 2) definir esquemas penales sancionatorios sobre aquellos que abusen del consumo (afectando a terceros principalmente), induzcan a menores de edad al consumo, o que distribuyan dichas sustancias por fuera de los canales regulados de distribución legal.

Aunque esos instrumentos pueden ser objeto de mayor análisis, ese análisis supera el alcance de este trabajo. No obstante, cabe indicar que una política adecuada debe limitar el abuso de sustancias sicoactivas (el problema esencial), sin pretender eliminar el consumo, pues ciertos usos de estas sustancias no son socialmente dañinos y obedecen a una decisión personal. Y como las políticas de control generan costos para la sociedad (problemas secundarios), una buena estrategia debe minimizar esos problemas secundarios. En este último espacio entraría a jugar el combate militar a los reductos de productores y distribuidores ilegales que no acepten las nuevas reglas de juego, los cuales, por la mera fuerza de la legalización regulada y el control sobre sus finanzas, reducirían su capacidad de adaptación ante dicha represión, y se arrancaría a las bandas criminales el rol de Estado en determinadas zonas urbanas o rurales que logran jugar cuando es la prohibición la que busca combatir un problema que se engendra, subyace y se reproduce en las raíces del territorio.

\section{CONCLUSIONES}

Los mecanismos que hacen posible que las bandas criminales coopten territorio son un elemento clave para entender la dinámica del narcotráfico en Colombia. El microtráfico es la máxima expresión de la relación drogas ilícitas/territorio, lo cual evidencia que las políticas de seguridad en el proceso de lucha contra los mercados de drogas 
ilícitas deben superar su focalización exclusiva en la oferta, ya que han tenido un bajo impacto en los negocios ilícitos y han potenciado la capacidad de inventiva de las redes de narcotráfico para apropiarse del territorio, expandir sus actividades hacia submercados criminales y, además, legitimar desde la territorialidad su quehacer productivo ilegal.

El narcotráfico, en su fase actual de desarrollo, caracterizado por la estructura binaria microtráfico-narcomenudeo es un proceso complejo donde interactúan estratégicamente varios tipos de agentes: los productores y traficantes, los agentes de defensa y corrupción, una serie de profesionales de diversa índole, que juegan un papel técnicoestratégico para el funcionamiento de la cadena, y, por último, los distribuidores al por menor de las drogas. Estos agentes interactúan en el contexto de estructuras sociales basadas en vínculos y redes sociales, soporte social del funcionamiento, reproducción y evolución de toda la cadena productiva.

El objetivo político y de seguridad de las organizaciones ilegales de microtráfico es el dominio del territorio con el propósito de ejercer control político, económico, social y militar, para disuadir y evadir a las autoridades de control y burlar la ley. Para ello, los empresarios ilegales han diseñado diversas y sofisticadas estrategias de dominio paramilitar, político y económico, empleando variopintos mecanismos de soborno, extorsión, corrupción, incluso la reconfiguración cooptada del Estado (Garay y Salcedo, 2012) y la corrupción de otras instituciones democráticas. El resultado de todo esto es la diversificación del riesgo en la ejecución de las actividades ilícitas, y una creciente resiliencia de las organizaciones ilegales frente a las autoridades de control en el contexto de la guerra contra las drogas.

La prohibición de las drogas convierte este mercado en un problema. Las drogas prohibidas son dañinas, para las personas y para la sociedad, además de ser económicamente y políticamente dañinas. Las drogas ilícitas son ante todo un problema de salud pública, que, por razones geopolíticas llevó a una guerra sin control ni datos precisos, subterránea y con efectos perversos sobre la estructura institucional y social, en particular de los países productores. El control de las finanzas de las bandas criminales y la legalización regulada del consumo de sustancias sicoactivas pueden ser instrumentos eficaces en dicha lucha, porque alteran la jerarquía del problema, de un orden criminal a uno de salud pública.

Del modelo analítico expuesto se infiere que las reacciones estratégicas de los agentes ilegales, incluyendo la implementación de 
estrategias de corrupción a las autoridades de control, a los políticos y a la sociedad en general, como estratagemas político-económicos de mediano y largo plazo, han permitido incrementar notablemente la eficiencia de toda la cadena productiva y, como resultado, han llevado al fracaso de las políticas de la represión a la oferta de drogas y la guerra contra las drogas en el largo plazo. ¿Por qué razón? Una explicación radica en las mutaciones constantes del narcotráfico como fenómeno complejo y dinámico: se comienza a atacar un fenómeno que al final ha cambiado en esencia.

En concreto, el modelo indica que niveles positivos de corrupción tienden a reducir la efectividad de las políticas represivas y, por tanto, llevar al resultado paradójico de que una mayor represión no aumenta sino que reduce la PDA de los traficantes.

Por otro lado, como se prueba en Raffo (2015), los gastos de los microtraficantes en corrupción potencian notablemente el impacto positivo de la expansión de las RTD en la venta de drogas ilegales y, en consecuencia, su impacto negativo en los precios. Así mismo, unas redes criminales más (menos) densas implican mayores (menores) ventas agregadas. Pero lo más importante a este respecto, como resultado del modelo, es que un aumento del gasto en corrupción, por parte de los microtraficantes, amplía el impacto de la mayor densidad de las RTD en la venta de drogas ilegales.

\section{REFERENCIAS BIBLIOGRÁFICAS}

1. Baker, W. y Faulkner, R. (1993). The social organization of conspiracy: Illegal networks in the heavy electrical equipment industry. American Sociological Review, 58(6), 837-860.

2. Ballester, C.; Calvó-A., A. et al. (2010). Delinquent networks. Journal of the European Economic Association, 8(1), 34-61.

3. Beltrán, I. (2014). Aprendizaje criminal en Colombia. Bogotá: Ediciones de la U.

4. Calderoni, F. (2011). Strategic positioning in mafia networks. Equipe de recherche sur la délinquance en réseau. [http://www.erdr.org/textes/ calderoni.pdf].

5. Calvó-A, A. y Zenou, Y. (2004). Social networks and crime decisions: The role of social structure in facilitating delinquent behavior. International Economic Review, 45(3), 939-958.

6. De León, I. y Salcedo, E. (2014). El crimen como oficio. Ensayos sobre economía del crimen en Colombia. Bogotá: Universidad Externado de Colombia.

7. De León, I. et al. (2016). Microtráfico y comercialización de sustancias psicoactivas en pequeñas cantidades en contextos urbanos. Bogotá: Ministerio de Justicia y del Derecho de Colombia - Observatorio de Drogas de Colombia. 
8. Duncan, G. (2005). Narcotraficantes, mafiosos y guerreros. Historia de una subordinación. A. Rangel (ed.), Narcotráfico en Colombia: economía $y$ violencia. Bogotá: Fundación Seguridad y Democracia.

9. Duncan, G. (2014). Más que plata o plomo. El poder politico del narcotráfico en Colombia y México. Bogotá: Penguin Random House Grupo Editorial.

10. Garay, L. J. y Salcedo, E. (2012). Narcotráfico, corrupción y Estados. Bogotá: Nomos Impresores.

11. Grossman, H. y Mejía, D. (2005). The war against drug producers. NBER Working Papers Series 11141, 1-24.

12. Hirshleifer, J. (1988). The analitics of continuing conflict. Synthese, 76(2), 201-233.

13. Hirshleifer, J. (1991a). The paradox of power. Economics and Politics, 3, 177-200.

14. Hirshleifer, J. (1991b). The technology of conflict as an economic activity. American Economic Association, 81(2), 130-34.

15. Mejía, D. y Restrepo, P. (2008). The war on illegal drug production and trafficking: An economic evaluation of Plan Colombia. Documentos CEDE, 19. [https://economia.uniandes.edu.co/components/com_booklibrary/ebooks/dcede2008-19.pdf].

16. Mejía, D. y Rico, D. (2011). La microeconomía de la producción y el tráfico de cocaína en Colombia. A. Gaviria y D. Mejía (eds.), Politicas antidroga en Colombia: éxitos, fracasos y extravios (pp. 15-40). Bogotá: Universidad de los Andes.

17. Morselli, C. (2009). Hells angels in springtime. Trends in organized crime, 12(2), 145-158.

18. Morselli, C. (2010). Assessing vulnerable and strategic positions in a criminal network. Journal of Contemporary Criminal, Justice, 26(4), 382-392.

19. Ortiz, C. H. (2002). Luchando infructuosamente contra la hidra: un modelo sencillo del narcotráfico. Cuadernos de Economía, (21)37, 1-22.

20. Poret, S. y Téjedo, C. (2015). Law enforcement and concentration in illicit drug markets. European Journal of Political Economy, 22(1), 99-114.

21. Raffo, L. (2015). La baja de largo plazo en los precios de las drogas duras: una explicación. Lecturas de Economía, 83, 63-96.

22. Raffo, L. y Segura, J. L. (2015). Las redes del narcotráfico y sus interacciones: un modelo teórico. Revista de Economía Institucional, 17(32), 183-212.

23. Ravelo, R. (2009). Osiel: vida y tragedia de un capo. México: Grijalbo.

24. Skaperdas, S. (1991). Conflict and attitudes toward risk. The American Economic Review, 81(2), 116-120.

25. Skaperdas, S. (1992). Cooperation, conflict and power in the absence of porperty rights. American Economic Review, 82(4), 720-739.

26. Skaperdas, S. (1996). Contest succes functions. Economic Theory, 7, 283-290.

27. Skaperdas, S. y Syropoulos, C. (1995). Gangs as primitive States. G. Fiorentini y S. Peltzman (eds.), The economics of organized crime (pp. 61-84). Cambridge, uk: Cambridge University Press. 
28. Skaperdas, S. y Syropoulos, C. (2001). Guns butter and openess: On the relationship between security and trade. American Economic Review, 91(2), 353-357.

29. Thoumi, F. (2015). Debates y paradigmas de las politicas de drogas en el mundo y los desafíos para Colombia. Bogotá: Academia Colombiana de Ciencias Económicas.

30. Tickner, A. et al. (2011). Actores violentos no estatales y narcotráfico en Colombia. A. Gaviria y D. Mejía (eds.), Politicas antidroga en Colombia: éxitos, fracasos y extravios. Bogotá: Universidad de los Andes.

31. unodc (2016). World Drug Report. Nueva York: United Nations. 